\title{
CONSTITUIÇÃO, INTERAÇÃO E DESENVOLVIMENTO REGIONAL DE UM ECOSSISTEMA EMPREENDEDOR: UM ESTUDO DO SAN PEDRO VALLEY
}

Henrique Cordeiro Martins ${ }^{1}$

Rachel Matos Dornelas ${ }^{2}$

${ }^{1}$ FUMEC - Fundação Mineira de Educação e Cultura

${ }^{2}$ FUMEC - Fundação Mineira de Educação e Cultura - SEBRAE-MG 


\section{CONSTITUIÇÃO, INTERAÇÃO E DESENVOLVIMENTO REGIONAL DE UM ECOSSISTEMA EMPREENDEDOR: UM ESTUDO DO SAN PEDRO VALLEY}

Resumo: O objetivo deste trabalho foi analisar os elementos relevantes e como eles interagem para a estruturação de um ecossistema que fomenta o empreendedorismo em uma região, bem como as estratégias que contribuem para o fortalecimento deste ecossistema. A pesquisa foi realizada em uma comunidade startups, localizada em Belo Horizonte, a San Pedro Valley. Foi utilizado o método qualitativo, por meio de entrevistas semiestruturadas a 18 instituições representativas do ecossistema. Concluiu-se que para um ecossistema saudável são necessários uma diversidade grande de atores e participantes, além de espaços próprios de conexão. A interação entre esses atores se dá basicamente por meio de eventos e mídias sociais, mas os resultados pontam como fragilidade as estratégias de fortalecimento por não ter uma estrutura organizada e governança representativa.

\section{Palavras-chave: Constituição. Interação. Desenvolvimento Regional. Ecossistema Empreendedor.}

\section{$1 \quad$ Introdução}

O empreendedorismo vem se consolidando, no cenário nacional, como um importante fator para o fortalecimento de territórios e empoderamento dos indivíduos. O protagonismo da sociedade é uma força que pode contribuir efetivamente para o desenvolvimento socioeconômico da nação e diminuir o abismo social.

Diante disso, compreender o significado de empreendedorismo, bem como desassociá-lo do simples ato de abrir uma empresa faz-se necessário para a pretensão desse trabalho. Assim como traz Dornelas (2008), no final do século XIX e início do século XX, os empreendedores foram frequentemente confundidos com gerentes ou administradores de empresas (o que ocorre até os dias atuais) sendo analisados meramente de um ponto de vista econômico, como aqueles que organizam empresas, pagam os empregados, planejam, dirigem e controlam as ações desenvolvidas na organização. Os empreendedores se diferenciam de gerentes ou estrategistas, porque acreditam que podem transformar o futuro, pois o mesmo ainda pode ser substancialmente moldado pela ação humana; e eles percebem que, na medida em que essa ação humana pode controlar o futuro, eles não precisam gastar energia tentando prever isso e, na medida em que o futuro é moldado pela ação humana, não é de muita utilidade tentar prever isso; é muito mais útil entender e trabalhar com as pessoas que estão engajadas nas decisões e ações que as trazem à existência. (Sarasvathy, 2003).

De acordo com Venkataraman (1997), apesar de a maioria dos pesquisadores terem definido empreendedorismo exclusivamente em termos de quem é o empresário e o que ele ou ela faz, a abordagem mais adequada deveria contemplar a conexão de dois fenômenos: a presença de oportunidades lucrativas e a presença de indivíduos empreendedores.

Também sobre oportunidades é a contribuição de Timmons (2011), que coloca a criação e ou o reconhecimento de oportunidades no centro do processo, seguidas pela vontade e iniciativa para aproveitar essas oportunidades. 
Para Dornelas (2007), empreendedorismo significa fazer algo novo, diferente, mudar a situação atual e buscar, de forma incessante, novas oportunidades de negócio, tendo como foco a inovação e a criação de valor. Em sua obra seminal de 1911, Teoria sobre o Desenvolvimento Econômico, Schumpeter considera que os empreendedores são a força motriz do crescimento econômico, ao introduzir no mercado inovações que tornam obsoletos os produtos e as tecnologias existentes.

É possível perceber que o conceito sobre empreendedorismo ainda poderá ser objeto de muitos estudos até que se tenha um consenso para a academia, a disciplina que abarcará suas teorias e para a sociedade para que possam compreender seu poder de transformação da realidade e geração de valor.

Assim, tem-se que empreendedorismo é uma maneira de pensar, raciocinar e agir (TIMMONS, 2011). E, a partir desse comportamento, criar valor para si e para a sociedade, como traz Anderson (2015), para quem o empreendedorismo é a criação de novo valor e, ao mesmo tempo, mudança e criação para o indivíduo ou, assim como traz Motomura (2004), empreendedorismo não é nada mais do que o poder de fazer as coisas acontecerem.

Uma vez que se assume o empreendedorismo como o encontro da oportunidade com o sujeito empreendedor, torna-se necessário entender o que faz com que esse encontro tenha como resultado a geração de valor para a sociedade. Para Dolabela (2007), o espírito empreendedor é um potencial de qualquer ser humano e necessita de algumas condições indispensáveis para se materializar e produzir efeitos. Entre essas condições estão, no ambiente macro, a democracia, a cooperação e a estrutura de poder tendendo para a forma de rede.

Segundo Olave e Amato Neto (2001), as redes de empresas representam uma forma inovativa de obter competitividade e sobreviver no mundo globalizado, assim, uma das principais características do atual ambiente organizacional é a necessidade de as empresas atuarem de forma conjunta e associada. Desta forma, surge como possibilidade concreta para o desenvolvimento empresarial, os modelos organizacionais baseados na associação, na complementaridade, no compartilhamento, na troca e na ajuda mútua, tomando como referência o conceito de redes advindo, principalmente, da sociologia.

A cooperação é um fator primordial para o impulsionamento do empreendedorismo, segundo Auerswald (2015), um ecossistema empresarial implica cooperação, produtividade e relacionamentos entre organizações diferentes. Em muitos países, estes relacionamentos são entre startups, empresas estabelecidas, universidades e instituições de pesquisa. Em um ecossistema vibrante, as pessoas e as ideias fluem entre essas organizações, iniciando novos empreendimentos, unindo os existentes, e associando-os a novos entrantes.

Para Isenberg (2011), a metáfora predominante para promover o empreendedorismo como estratégia de desenvolvimento econômico é o "ecossistema de empreendedorismo" e, no cerne da estratégia do ecossistema empreendedorismo, está a visão de quais fatores compõem o ecossistema de empreendedorismo e como ele evolui.

Nestes termos, Mason e Brow (2014, p.5) definem um Ecossistema Empreendedor como "um conjunto de atores empresariais interligados, organizações empresariais, instituições (universidades, agências do setor público, órgãos financeiros) e processos empresariais que se fundam formalmente e informalmente para se conectar, mediar e governar o desempenho dentro do ambiente". 
Sendo assim, para que o empreendedorismo seja disseminado e arraigado em uma sociedade, é necessário que os empreendedores, principais atores da função empreendedora, promovam um ambiente de cooperação e coopetição. Diante do exposto, a pergunta de pesquisa que norteia este trabalho é: Quais são os elementos de constituição, interação e estratégias no desenvolvimento de um ecossistema empreendedor?

Desta forma, o objetivo deste trabalho foi analisar os elementos relevantes e como eles interagem para a estruturação de um ecossistema que fomenta o empreendedorismo em uma região, bem como as estratégias que contribuem para o fortalecimento deste ecossistema. $\mathrm{O}$ objeto de estudo escolhido para o desenvolvimento desse trabalho foi a comunidade de startups mineira autodenominada San Pedro Valley (SPV), cujo nome faz uma alusão à comunidade de startups norte americana Silicon Valley ou Vale do Silício.

Este estudo se justifica pela força poderosa que o empreendedorismo se transformou e vem ganhando atenção do poder público, da academia e da sociedade civil devido aos impactos que vem causando na sociedade. De acordo com a pesquisa Global Entrepreneurship Monitor (GEM), no Brasil, em 2016, cerca de 36\% dos indivíduos adultos estavam envolvidos com alguma atividade empreendedora e/ou estavam realizando alguma ação visando ter o seu próprio negócio (GEM 2016).

De acordo com Auerswald (2015), a pesquisa acadêmica atual não fornece respostas prontas ou até mesmo arcabouços conceituais para fazer perguntas relevantes, fazendo com que a busca por estratégias para viabilizar ecossistemas empresariais locais seja fundamentalmente práticas, apontando para a necessidade de uma melhor compreensão dos ecossistemas para que os formuladores de políticas possam fazer perguntas relevantes, vislumbrar melhores abordagens e avaliar de forma significativa as conclusões resultantes.

Além desta introdução, este estudo consta de revisão da literatura. Na sequência, é apresentada a metodologia da pesquisa e, posteriormente, são expostos os dados e a discussão dos resultados da pesquisa e as considerações acerca do estudo.

\section{Referencial Teórico}

\section{1 - Empreendedorismo: perspectivas, abordagens e alcance}

Timmons (2011) já vislumbrava a relevância da função empreendedora ao dizer que o empreendedorismo é uma revolução silenciosa, que será para o século XXI mais do que a Revolução Industrial foi para o século XX.

Em todas as edições passadas a GEM sempre traz a importância do Empreendedorismo como fator determinante para o desenvolvimento das nações. $O$ desenvolvimento do empreendedorismo tem sido enfatizado nos meios acadêmico e empresarial como fundamental para o desenvolvimento econômico dos países (GEM, 2017). São 15,7 milhões de jovens que estão levantando informações para ter um negócio ou que já têm empresa com até três anos e meio de atividade, um aumento de 7 pontos percentuais, na participação relativa, na comparação com 2016. Os números revelam ainda que um em cada três adultos brasileiros, entre 18 e 64 anos, é empreendedor ou está envolvido na abertura do próprio negócio. O percentual de brasileiros que empreendem por oportunidade também aumentou, de $57 \%$ para $59 \%$. A Taxa de Empreendedorismo Inicial (TEA) chegou a 19,6\%, ficando o Brasil na $8^{\text {a }}$ colocação no grupo dos 32 países "impulsionados por eficiência" e na $10^{\text {a }}$ colocação geral dos 65 países pesquisados. Portanto, as taxas de empreendedorismo no Brasil são consideradas relativamente 
altas, por exemplo, superior às encontradas em países como Argentina, México, os BRICS (Rússia, Índia, China e África do Sul), Estados Unidos, França, Espanha, Alemanha e Itália. Porém, ainda segundo a GEM (2017), a "qualidade" desse contingente de empreendedores é inferior à dos demais países, quando considerados itens como, por exemplo, o baixo grau de inovação dos produtos e sua baixa inserção/competitividade internacional.

Além da expressiva participação no total de pessoas ocupadas, os pequenos negócios exercem relevante papel como "colchão social" em períodos de crise da economia. Por exemplo, de acordo com a PNADC - Pesquisa Nacional por Amostra de Domicílios Contínua - entre o $1^{\circ}$ trimestre de 2014 e o $1^{\circ}$ trimestre de 2017 , dobrou o contingente de pessoas desempregadas (de 7 milhões para 14 milhões de pessoas), aumentando a taxa total de desemprego de $7 \%$ para $13,7 \%$. No mesmo período, o total de empregadores por conta própria aumentou em 1,6 milhão de pessoas.

Andrade (2017), traz os dados de uma pesquisa sobre a temática - Ecossistema Empreendedor - em várias plataformas de pesquisa acadêmica que a levou aos seguintes resultados - em pesquisa realizada em fevereiro de 2017 no site da Associação Nacional de Pós-Graduação e Pesquisa em Administração (ANPAD) sobre o assunto "ecossistema empreendedor" não retornou resultados. Busca efetuada na base da Scientific Periodicals Eletronic Library (SPELL) com temática sobre ecossistema empreendedor retornou 4 resultados. Pesquisa semelhante realizada na Scientific Electronic Library online (Scielo), retornou 04 resultados para os temas: "empreendedorismo e startups", 01 resultado para os termos conjuntos de "empreendedorismo e ecossistema empreendedor". Quando se pesquisou resultados na Biblioteca Digital de Teses e Dissertações (BDTD), mantida pelo Instituto Brasileiro de Informação em Ciência e Tecnologia (IBICT), foram encontrados 09 trabalhos, entre teses e dissertações, sobre as temáticas do empreendedorismo e ecossistema.

Foi realizado um resgate conceitual histórico ao longo das décadas para organizar pensadores e suas ideias em grandes temas e correntes. Uma linha do tempo foi imaginada com base em trabalhos seminais essenciais para a compreensão do termo, desde 1755, quando o termo entrepreneur surgiu na França até 2005, quando Baker e Nelson introduziram a teoria da Bricolagem.

Considerando uma linha do tempo, Cantillon é o primeiro a explorar o conceito, tratando-o em um viés econômico. Em 1912, Schumpeter traz sua contribuição sobre o empreendedorismo corroborando com a ideia da força econômica ao associar os empreendedores à inovação e sua importância para o desenvolvimento econômico (FILION, 1999). McClelland, já nos anos 60, traz sua contribuição à luz das ciências do comportamento identificando os empreendedores por meio de uma série de características e comportamentos (FILION, 1999). Em 1989, Gartner lança o trabalho "Who is an Entrepreneur? Is The Wrong Question." Colocando em xeque a teoria dos traços de personalidade de McClelland. Para o autor pesquisas em empreendedorismo deveriam focar no que o empreendedor faz e não em quem ele é. Seguindo com a linha do tempo, em 1997, Kirzner alerta para a importância do conhecimento, da oportunidade e da descoberta empreendedora no processo de equilíbrio do mercado, por meio da abordagem Austríaca (ARRUDA et al., 2015). Também sobre oportunidade, descoberta e exploração é a contribuição de Shane e Venkataraman (2000), que assumem o empreendedorismo como sendo um comportamento transitório, que envolve, fundamentalmente, a descoberta, a avaliação e a exploração das oportunidades. Para os autores 
o comportamento empreendedor é circunstancial, não sendo composto por um grupo de características que diferenciam algumas pessoas de outras em todas as situações, corroborando assim com o trabalho de Gartner e deixando no passado a teoria sobre traços de comportamento de McClelland (ARRUDA et al., 2015).

Sarasvasthy e a dupla de autores Baker e Nelson, em uma abordagem mais contemporânea, trazem suas contribuições para o estudo do empreendedorismo ao abordarem os processos de Effectuation e Bricolagem. (ARRUDA et al., 2015).

\section{2 - Ecossistema Empreendedor}

Há vários exemplos de configurações entre grupos empresariais, no entanto, os mais comuns na literatura são os clustters, APLs - Arranjos Produtivos Locais e Distritos Industriais. (SEBRAE, 2004). O termo ecossistema foi originalmente cunhado por James Moore em um artigo na Harvard Business Review, publicado durante a década de 1990. Para Moore, uma empresa não deve ser como um membro de uma única indústria, mas como parte de um ecossistema de negócios onde as empresas co-evoluem trabalhando cooperativamente e competitivamente para apoiar novos produtos, satisfazer as necessidades dos clientes e, eventualmente, incorporar a próxima rodada de inovações. Ainda segundo o autor, as empresas bem-sucedidas devem atrair recursos de todos os tipos, desenho em capital, parceiros, fornecedores e clientes para criar redes cooperativas. (MOORE, 1993, p.76).

O ecossistema empreendedor, assim como traz Carvalho et al. (2016), é atualmente considerado como um espaço regional que inclui um conjunto diversificado de intervenientes institucionais e individuais, fomentando o espírito empresarial, a inovação e o empreendedorismo. Este espaço regional encerra um conjunto diversificado de atores que se incluem, de acordo com o modelo da Hélice Tríplice, associadas a três dimensões: governouniversidade-empresas.

O ecossistema empreendedor contempla, dentre outros conceitos, a evolução ou mesmo, agrega a Tríplice Hélice - trinômio envolvendo organizações com finalidades diferentes, mas em busca de um mesmo propósito, o modelo de Tríplice Hélice traz a compreensão das relações institucionais que podem promover o desenvolvimento tecnológico e sustentável. Etzkowitz e Zhou (2017), definem a Hélice Tríplice como um modelo de inovação em que a universidade/academia, a indústria e o governo, como esferas institucionais primárias, interagem para promover o desenvolvimento por meio da inovação e do empreendedorismo.

Uma das principais referências no estudo sobre Ecossistema Empreendedor é o Professor Daniel J. Isenberg, associado à Babson College, nos EUA, uma das mais importantes escolas de empreendedorismo do mundo. O professor Isenberg (2010) propôs um modelo de Ecossistema Empreendedor que abrange seis domínios fundamentais para a formação de um ecossistema empreendedor - Políticas Públicas, Capital Financeiro, Cultura, Instituições de Suporte, Recursos Humanos e Mercados (FIG.1).

De acordo com Arruda, Burcharth (2015), os seis domínios do modelo de ecossistema empreendedor de Isenberg contemplam os seguintes elementos: No âmbito das Políticas Públicas estão inseridas as instituições governamentais de apoio ao empreendedorismo, sejam elas universidades públicas, que assumem um papel importante gerando conhecimento que poderá eventualmente ser levado ao mercado na forma de produto ou, ainda, órgãos de 
regulamentação responsáveis por implantar incentivos ou retirar barreiras burocráticas para estimular o desenvolvimento empresarial.

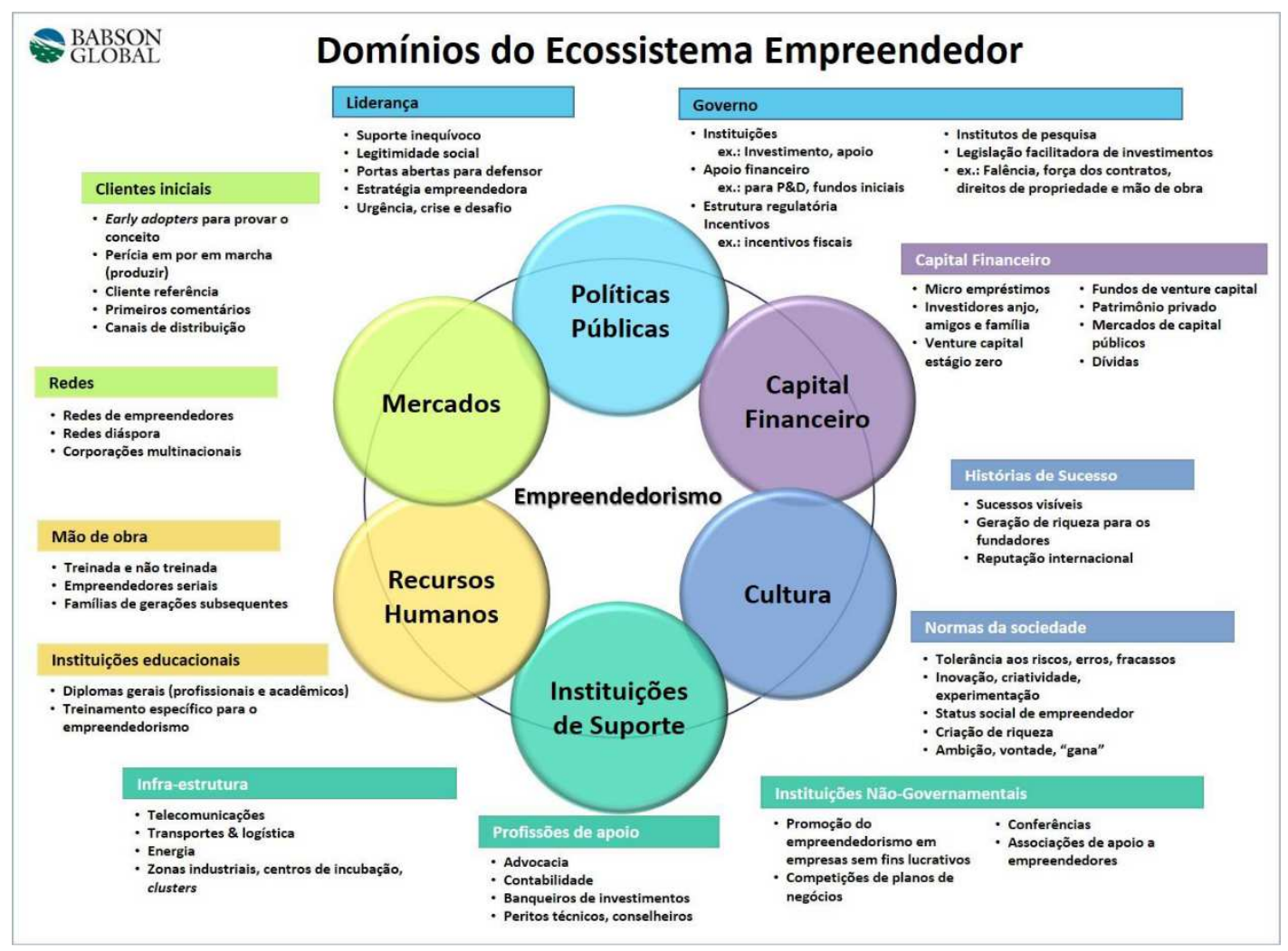

FIGURA 1 - Domínios do Ecossistema Empreendedor.

Fonte: Adaptação do modelo de Daniel Isenberg (2011).

$\mathrm{Na}$ esfera de Capital Financeiro, encontram-se as instituições privadas responsáveis pelo financiamento do empreendedorismo, como investidores anjos, fundos de capital de risco e capital semente, entre outros. A Cultura abrange todas as características sociais de uma comunidade e os aspectos subjetivos relacionados à forma como os indivíduos se relacionam, o que recriminam e o que é motivo de reconhecimento. Já no âmbito das Instituições/Profissões de Suporte encontram-se instituições que não estão ligadas ao governo e que fazem o papel de incentivadoras do empreendedorismo como HUBs, aceleradoras, incubadoras além de escritórios de contabilidade e advocacia, por exemplo, necessários para dar suporte na estruturação de novas empresas. Os Recursos Humanos incluem tanto os profissionais qualificados por meio da educação voltada para o empreendedorismo, quanto a mão de obra composta pela massa, necessidade intrínseca de um mercado que visa o progresso econômico por meio da criação de novas empresas. A esfera dos Mercados, por fim, aborda a necessidade da existência de consumidores prontos para absorver novos produtos e disseminá-los por meio de uma rede de contatos tanto nacional, como internacionalmente.

Os ecossistemas de empreendedorismo são ambientes delimitados geograficamente complexos e de caráter evolutivo, holístico e dinâmico. Um ecossistema de empreendedorismo, portanto, é o resultado da interação entre os seus atores, os quais evoluem juntos e se reforçam 
mutuamente (Isenberg, 2011). Segundo Isenberg (2011) não é possível reproduzir os resultados de um determinado ecossistema em outro local, por isso, ainda de acordo com Isenberg (2010) não há uma fórmula exata para criar uma economia empreendedora; existem apenas práticas, se não imperfeitas, ou mesmo, indicações de caminhos possíveis.

\section{$3 \quad$ Metodologia da Pesquisa}

A pesquisa foi realizada na comunidade digital San Pedro Valley, localizada em Belo Horizonte, Minas Gerais, Brasil. Para isto, foi realizada uma pesquisa de natureza qualitativa, do tipo descritiva, por meio de múltiplos casos. A unidade de observação foram as empresas que pertencem ao ecossistema analisado e as unidades de análises foram os atores que compõe estas empresas. Estes atores foram selecionados de acordo com as dimensões do modelo de Isenberg: Políticas públicas, Capital financeiro, Cultura, Instituições de suporte, Recursos humanos e Mercado. A coleta de dados deu-se por meio de entrevista semiestruturada e a análise dos dados por meio da análise de conteúdo.

A pesquisa foi realizada com 18 empresas, pessoalmente ou via internet. O roteiro da entrevista foi estruturado em 4 blocos que buscaram investigar sobre a Interação entre os atores; a Colaboração entre os atores; o Impacto no desenvolvimento da região e as Estratégias para o fortalecimento do ecossistema. As 18 empresas entrevistadas buscaram contemplar representantes dos 6 domínios do modelo de ecossistema de Isenberg (Quadro 1).

Quadro1 - Caracterização das instituições entrevistadas
\begin{tabular}{|l|l|l|l|}
\hline $\begin{array}{l}\text { Entrevis- } \\
\text { tado }\end{array}$ & Cargo & Descrição do Negócio & $\begin{array}{l}\text { Tipo } \\
\text { Negócio }\end{array}$ \\
\hline 1 & Gerente & $\begin{array}{l}\text { Programa de aceleração que aproxima as startups da indústria mineira, para } \\
\text { que juntas criem negócios de sucesso no mercado. }\end{array}$ & Aceleradora \\
\hline 2 & Fundador & $\begin{array}{l}\text { Startup de lavanderia online que funciona por meio de assinatura de planos } \\
\text { mensais. }\end{array}$ & Startup \\
\hline 3 & Fundador & Plataforma para envio de SMS em massa e gestão inteligente de contatos. & Startup \\
\hline 4 & Sócio & $\begin{array}{l}\text { Um dos primeiros escritórios de Belo Horizonte que formatou uma equipe } \\
\text { de advogados para prestar assessoria completa a startups. }\end{array}$ & Advocacia \\
\hline 5 & $\begin{array}{l}\text { Coordenador } \\
\text { de Equipes }\end{array}$ & $\begin{array}{l}\text { Programa de aceleração de startups criada em um programa do Governo de } \\
\text { Minas Gerais. }\end{array}$ & $\begin{array}{l}\text { Programa de } \\
\text { Aceleração }\end{array}$ \\
\hline 6 & Fundador & $\begin{array}{l}\text { Plataforma de e-commerce e implantadora certificada Magento que fornece } \\
\text { soluções variadas para o segmento de lojas virtuais. }\end{array}$ & Startup \\
\hline 7 & CEO & $\begin{array}{l}\text { Escola de programação cuja missão é trazer habilidades técnicas para } \\
\text { pessoas criativas. }\end{array}$ & Startup \\
\hline 8 & CEO & $\begin{array}{l}\text { Primeira pré-aceleradora com foco em games do mundo sendo a ponte } \\
\text { entre estúdios desenvolvedores de games e investidores globais }\end{array}$ & $\begin{array}{l}\text { Pré- } \\
\text { Aceleradora }\end{array}$ \\
\hline 9 & Fundador & $\begin{array}{l}\text { Startup de desburocratização do comércio exterior Latino Americano por } \\
\text { meio de conexão protegida com criptografia e certificação digital. }\end{array}$ & Startup \\
\hline 10 & CEO & $\begin{array}{l}\text { Plataforma para comparar os planos de celular das principais operadoras } \\
\text { disponíveis em BH. }\end{array}$ & Startup \\
\hline 11 & $\begin{array}{l}\text { Gerente de } \\
\text { Projetos }\end{array}$ & $\begin{array}{l}\text { Apresenta-se basicamente em dois formatos: educação e aceleração de } \\
\text { startups. }\end{array}$ & $\begin{array}{l}\text { Formação de } \\
\text { RH }\end{array}$ \\
\hline 12 & Diretor & $\begin{array}{l}\text { Espaço que tem como objetivo conectar empreendedores, startups, } \\
\text { investidores, instituições de ensino e o mercado. }\end{array}$ & Cowork \\
\hline 13 & Poordenadora & $\begin{array}{l}\text { Espaço idealizado para aprimorar ou desenvolver novos produtos, } \\
\text { processos e negócios. }\end{array}$ & $\begin{array}{l}\text { Laboratório } \\
\text { Aberto }\end{array}$ \\
\hline
\end{tabular}




\begin{tabular}{|l|l|l|l|}
\hline 15 & $\begin{array}{l}\text { Coordenador } \\
\text { e idealizador }\end{array}$ & $\begin{array}{l}\text { Programa de pré-aceleração de startups realizado pela Fundep e Fundepar, } \\
\text { co-realizado pelo Techmall, SEBRAE, FAPEMIG e Governo de Minas por } \\
\text { meio do Simi. }\end{array}$ & $\begin{array}{l}\text { Programa de } \\
\text { Pré- } \\
\text { Aceleração }\end{array}$ \\
\hline 16 & Gerente & $\begin{array}{l}\text { Entidade associativa de direito privado, sem fins lucrativos que oferece } \\
\text { orientação. }\end{array}$ & $\begin{array}{l}\text { Empresa de } \\
\text { fomento }\end{array}$ \\
\hline 17 & Fundador & $\begin{array}{l}\text { Startup que tem o propósito de cuidar do lixo do mundo, e desenvolve } \\
\text { tecnologias para a gestão de resíduos. }\end{array}$ & Startup \\
\hline 18 & Fundador & Startup que é agenda digital para instituições de ensino & Startup \\
\hline
\end{tabular}

Fonte: Dados da pesquisa, 2018

\section{1 - A descrição do Ecossistema San Pedro Valley}

O objeto de estudo escolhido para o desenvolvimento desse trabalho é a comunidade de startups mineira autodenominada San Pedro Valley (SPV), cujo nome faz uma alusão à comunidade de startups norte americana Silicon Valley ou Vale do Silício. A San Pedro Valley é uma comunidade de empresas e projetos de base tecnológica, idealizada em 2011, durante encontros informais dos empreendedores fundadores das startups Beved, Deskmetrics, Everwrite e Hotmart, que compõem a primeira geração do ecossistema cujo objetivo é reunir as startups de Belo Horizonte para identificar oportunidades, necessidades e incentivos (SAN PEDRO VALLEY, 2018).

Segundo Monttenegro (2016), um dos empreendedores que participaram da concepção da comunidade, com a startup Beved, San Pedro Valley surgiu de forma despretensiosa, como uma "brincadeira que acabou virando coisa séria".

Havia uma padaria localizada no bairro São Pedro onde, em muitas ocasiões, fundadores das principais startups do SPV se encontravam; em um desses encontros, salvo engano o Mateus Bicalho, um dos fundadores da Hotmart, proferiu a frase que ficaria eternizada na estória da comunidade "Nossa, aqui parece o Vale do Silício, toda hora esbarramos com um CEO de uma startup. Aqui é o San Pedro Valley.

Desde então a comunidade de startups de Belo Horizonte e região metropolitana se auto intitula San Pedro Valley. De acordo com Pacelli (2012), o San Pedro Valley é uma comunidade de novas empresas, com base tecnológica e ideias inovadoras, criada em torno do polo de uma universidade, em um ambiente de extrema incerteza. As veteranas se desenvolveram dentro de núcleos da Universidade Federal de Minas Gerais (UFMG), como a Akwan, adquirida pela Google em 2006.

Atualmente o SPV possui empresas de diversos setores, dentre elas 6 aceleradoras, 5 incubadoras, 58 agências digitais - empresas que oferecem serviços digitais como a criação de sites, 4 investidores - fundos de investimento de capital de risco, 18 coworks, 2 hackerspaces espaços focados na pesquisa e desenvolvimento de tecnologia e inovação além de 422 startups de acordo com o site da comunidade, o mesmo possui uma atualização automática para cadastro de instituições, entretanto, sua última atualização de conteúdo foi feita no início de 2017 (SAN PEDRO VALLEY, 2018).

Ainda segundo as informações do site do San Pedro Valley, o SPV é uma comunidade independente e auto gerenciada, com o propósito de colocar empreendedores da Região Metropolitana de $\mathrm{BH}$ em contato uns com os outros, buscar soluções para problemas em comum, trocar experiências e fortalecer o ecossistema empreendedor de Minas Gerais. A comunidade não responde ou pertence a qualquer sigla e coligação política e se posiciona como 
independente não sendo controlada por nenhuma entidade, partido, coligação ou interesse político de direita, esquerda, centro, situação ou oposição (SAN PEDRO VALLEY, 2018).

De acordo com João Pedro Resende, um dos fundadores da Hotmart startup de commerce para conteúdos digitais e um dos casos de sucesso do SPV "(a startup) é o modelo mais arriscado de negócios, mas também o mais vibrante", afirma. (PACELLI, 2012).

Monttenegro (2016), ainda traz a importância da atuação dos demais atores de Belo Horizonte para o fortalecimento do ecossistema, segundo ele, um fato importante é que a pujança do SPV fez com que vários atores do ecossistema se aproximassem, como o Sebrae, precursor dessa aproximação, seguido pelo Governo do Estado e a FIEMG.

San Pedro Valley se tornou uma mentalidade, uma cultura. A cultura da colaboração, de ajudar as pessoas sem esperar nada em troca. Transcende o grupo de amigos e pessoas próximas que se ajudavam mutuamente sem esperar nada em troca, isso não existe mais, uma vez que cada um está focado no seu negócio que não são mais startups e faturam $R \$ 10,20$ ou 30 milhões, cada. O SPV, hoje, é um exemplo de comunidade, crescimento orgânico, amizade, cumplicidade, apesar de não ser completo e maduro como outras comunidades e regiões ao longo do globo. (MONTTENEGRO, 2016).

\section{$3 \quad$ Resultados da Pesquisa}

As entrevistas com os representantes das instituições 1, 2, 4, 5, 6, 7, 9, 10, 12, 13, 14, 15 , 16,18 , foram realizadas pessoalmente, os demais - entrevistados $3,8,17$ responderam às perguntas via Hangout ou Skype. As entrevistas duraram em média 45 minutos.

Os representantes das instituições entrevistadas trouxeram sua percepção sobre a comunidade San Pedro Valley e suas contribuições. Neste primeiro momento já é possível perceber uma sensível diferença de opinião entre os empreendedores da primeira geração e os empreendedores que estão se estabelecendo, esta divergência, pode-se inferir, que se deve ao sentimento de pertencimento da comunidade, uma vez que sua origem foi criada por um grupo de amigos, fundada em pilares de confiança e amizade porém, no entanto, a percepção sobre a coesão dessa comunidade e sua contribuição efetiva para as outras gerações é um ponto conflituoso entre os atores.

O que se pode perceber é que há o orgulho de pertencimento por parte dos empreendedores, por ser uma marca forte e possuir um status quo, como pode ser percebido na fala do Entrevistado 9 "SPV é muito mais um orgulho mineiro do que uma associação estruturada. Não é oficial, não existimos enquanto associação", mas também percebe-se uma certa frustração pelo que o SPV poderia ter sido enquanto propósito mas (ainda) não conseguiu se articular para se tornar, no sentido dos benefícios que poderia trazer para as instituições e a sociedade".

Uma das questões identificadas, que traz uma importante contribuição sobre a compreensão da comunidade, se refere à sua delimitação que, devido ao nome fazer alusão a um bairro da zona sul de Belo Horizonte, a comunidade extrapola esse limite geográfico uma vez que está presente em vários bairros de Belo Horizonte e região metropolitana.

A leitura de bairro é uma leitura equivocada. O nome do bairro é um nome fantasia, ele está em Contagem, Betim, na Pampulha, na RMBH. (Entrevistado 1).

De toda forma, apesar dos relatos sobre a percepção de irrelevância da atuação da comunidade serem expressivos, pode-se perceber que o movimento gerado com sua criação trouxe ganhos consideráveis para a comunidade no sentido de revelar a capacidade 
mobilizadora da sociedade civil e a sua força de transformação, como foi dito pelos entrevistados:

O SPV é uma ideia força que se expressa na nomenclatura de comunidade para promover eventualmente coisas legais. Que gera um amálgama comunitário, é uma ideia força que gera vínculos comunitários . O ganho é intangível, comportamental. É a criação de uma geração (Entrevistado 1).

Ele é vivo, é orgânico, veio de baixo para cima, ele foi feito pelas pessoas e aí as instituições entenderam. (Entrevistado 15).

A partir dessas respostas, pode-se perceber a importância do San Pedro Valley como ponto de partida dos empreendedores, no entanto, em termos de articulação política e estratégia efetiva de fortalecimento para as instituições que fazem parte da comunidade o San Pedro Valley ainda apresenta uma atuação incipiente que, pode-se inferir, ser resultado de uma falta de governança, mesmo que a essência da comunidade seja uma instituição sem líderes.

Algumas incursões do governo ou de líderes situacionais têm sido feitas, de forma isolada, no entanto, não há um consenso da estratégia mais eficaz para esse desafio. Para Isenberg (2012), enquanto os governos têm o mandato de intervir, eles não têm necessariamente a competência para fazê-lo efetivamente, por isso, para ele, a intervenção deve ser criada por uma nova organização - um capacitador empreendedor.

O capacitador empreendedor, ainda por Isenberg (2011), precisa de competência e motivação para melhorar o ecossistema, cuja organização deveria ter um mandato público; o treinamento; os recursos. Teria que ser independente, não pertencente a nenhuma parte da comunidade. Saberia como experimentar, aprender, reorientar, dimensionar e derivar atividades. Seria responsável por atingir um ponto de inflexão em que a intervenção não é mais necessária. E seria temporário, com uma vida útil e data de validade claras.

Após os relatos dos entrevistados sobre suas instituições e suas percepções sobre o SPV, a primeira pergunta da pesquisa tratou de investigar sobre os atores relevantes para a estruturação de um ecossistema que fomenta o empreendedorismo em uma região, para este questionamento, todas as empresas citaram mais de um elemento.

Das 18 empresas entrevistadas, 17 citaram as aceleradoras como fundamental ao desenvolvimento do empreendedorismo, 17 os espaços de coworking, 12 citaram os investidores, 12 as universidades, 11 citaram o governo, principalmente, por meio de seus programas de aceleração, 9 as entidades de suporte e fomento, 10 citaram os empreendedores/fundadores e as respectivas startups e 9 os clientes, mercado e sociedade.

Com base nas respostas dadas pelos entrevistados, é possível identificar que todos os domínios do modelo de ecossistema empreendedor de Isenberg - NEGÓCIOS (clientes), CAPITAL (investidores), POLÍTICAS (governo), PESSOAS (instituições de formação de mão de obra/Universidade), SERVIÇOS (espaços de cowork, instituições de fomento e apoio) foram contemplados nas citações, assim como demonstrado na tabela 2, a dimensão CULTURA foi mencionada ao longo dos relatos, como por exemplo os casos de sucesso das startups da primeira geração e atualmente grandes empresas como a Sympla, Sambatech e Hotmart dentre outras.

Outra característica cultural advinda e disseminada pela própria comunidade SPV e citada ao longo das entrevistas foi o senso de retribuição para a sociedade ou o Give Back e Give First, particularidade das comunidades de startups como traz Mason e Brown (2014). É uma filosofia 
de inclusão. Uma atitude de "dar-antes-de-você-conseguir" está embutida na comunidade de startups, na cultura de compartilhar amplamente a experiência e o conhecimento.

Buscou-se identificar, também, quem são esses atores citados, tendo como resposta as aceleradoras e os programas de aceleração que têm como finalidade, de acordo com Ferreira e Pereira (2017), apoiar o crescimento das startups através de recursos técnicos e financeiros. As aceleradoras públicas utilizam de editais promovidos por entidades autorizadas como processo de seleção e as aceleradoras privadas possuem processos de seleção próprio. Segundo o Entrevistado 1 "(as aceleradoras) são os grandes polinizadores, precisam acolher o empreendedor e dar o primeiro tratamento".

Dentre as aceleradoras e os programas de aceleração mais citados estão: A Acelera MGTI, de responsabilidade da Fumsoft, é uma aceleradora especialista em potencializar empreendimentos de inovação e negócios globais. Uma estrutura completa para empreender novos negócios e apoiar o desenvolvimento de empresas. O Lemonade, um programa de aceleração de ideias e tecnologias em estágio inicial, que tem o objetivo de difundir a ciência na sociedade por meio da criação e desenvolvimento de negócios de alto impacto. O SEED Startups and Entrepreneurship Ecosystem Development, uma aceleradora de startups, que tem ideias inovadoras e estão entre as melhores. O SEED MG foi criado pelo Governo de Minas Gerais em busca de empreendedores do mundo inteiro, que acarretam novas aprendizagens e compartilham experiências, sonhos, ideias e principalmente a determinação de construir algo inovador com uma boa ideia de negócio. A TECHMALL, uma aceleradora de startups que surgiu para ser fonte de oportunidade, conexões e conhecimento para o desenvolvimento de startups globais.

Os Espaços de Coworking, assim como traz Campos, Teixeira e Schmitz (2015), podem ser definidos por ambientes que possibilitam o desenvolvimento de negócios, da colaboração da geração de networking, da expressão individual, coletiva, organizacional e da interação, tendo como base os valores do compartilhamento, da flexibilidade, da abertura para novas oportunidades, de um modelo mental propício para a economia criativa, colaborativas e para a inovação, sendo muito mais que um espaços físico gerador de facilidades estruturais para o desenvolvimento de negócios. Podem ser os labs, os university labs, as incubadoras, home office, coffee shops, coletivos, lab coworking ou coworking para a inovação, os coworking spaces, em sua versão clássica, os corpoworking, quando estes espaços estão situados dentro de corporações.

Os espaços de cowork mais mencionados nas entrevistas foram: Atmosphera, que é um ambiente capaz de aliar marcas com visão estratégias de inovação e empreendedores comprometidos em construir o futuro. BeerORcoffee, um aplicativo que reúne os espaços de cowork tendência que está modificando a forma com que empresas e empreendedores trabalham, compartilham e relacionam entre si. Ele define um ambiente de trabalho onde várias pessoas, que podem ser de diversas áreas de atuação, trabalham e compartilham suas ideias. Muito mais do que interação presencial, o compartilhamento é parte fundamental nesses ambientes. O Guaja, uma plataforma criativa e efervescente de empreendedorismo, conexão e aprendizado, onde empreendedores e criadores embarcam para trabalhar em um ambiente colaborativo. O Impact HUB, um espaço de cowork conectado local e globalmente a um ecossistema de pessoas, inspirações e recursos para concretizar ideias empreendedoras de impacto sustentável. O Órbi, um espaço colaborativo de fomento à inovação e ao 
empreendedorismo, onde startups em diferentes níveis de maturidade, terão um ambiente fértil em conexões para construir uma trajetória de crescimento e sucesso. É o resultado de uma parceria da Localiza com a MRV. O Raja Valley que disponibiliza diferentes alternativas de ocupação, passando por espaços de cowork com estações de trabalho para empreendedores individuais e pequenas empresas, aluguel de salas privativas em diversas dimensões, andares corridos, salas de reunião e espaço para eventos. Independente do seu tamanho. O FIEMG Lab, um programa de aceleração que aproxima as startups da indústria mineira, para que juntas criem negócios de sucesso no mercado, troquem experiências e gerem soluções para a sociedade, bem como competitividade e diversificação para a economia. O SENAI Lab Aberto, um ambiente de aprendizado criado para receber pessoas com diferentes perfis e habilidades. A Anjos do Brasil, uma organização sem fins lucrativos com o objetivo de fomentar o crescimento do investimento anjo para o apoio ao empreendedorismo de inovação brasileiro. $\mathrm{O}$ investimento anjo é feito por pessoas físicas e com seu capital próprio em startups.

As Universidades foram citadas por 12 entrevistados sendo que a Universidade Federal de Minas Gerais (UFMG) foi unânime em todas as entrevistas, tendo feito parte da formação de grande parte dos entrevistados. A relação virtuosa da UFMG e da comunidade no sentido de formar a mão de obra que irá criar negócios digitais no SPV e depois voltarão para contribuir com seu conhecimento de mercado.

Os Empreendedores/Fundadores e suas respectivas startups foram citados por 10 entrevistados que mencionaram ou o nome do empreendedor ou o nome da empresa, das quais as mais citadas e os respectivos fundadores, estão: A MAXMILHAS, empresa que se apresenta como uma plataforma digital que amplia o acesso às passagens aéreas conectando aqueles que possuem milhas aéreas - clientes ativos nos programas de fidelidade -, aos que desejam adquirilas. O empreendedor da MaxMilhas é o Max Oliveira. A SAMBATECH, por meio de seu fundador, Gustavo Caetano, é uma das embaixadoras do San Pedro Valley, e referência no mercado de vídeos online e infraestrutura para venda, distribuição, gerenciamento e armazenamento de vídeos. A SYMPLA uma plataforma completa para venda de ingressos e inscrições e gestão de eventos para qualquer tipo de evento: shows, festas, cursos, congressos, eventos esportivos, religiosos, gastronômicos e muitos mais. Líder no segmento "do it yourself" no Brasil, as soluções simplificam a forma de administrar as etapas do evento, seu fundador é Rodrigo Cartacho. A MELIUZ portal que disponibiliza, gratuitamente, cupons de desconto das melhores lojas online do Brasil e ainda devolve parte do valor gasto em compras, direto em conta bancária. Olif Guimarães e Israel Salmen são os fundadores da Meliuz. A HOTMART se apresenta como uma plataforma especialmente planejada para que todos possam mudar as suas vidas através da venda e distribuição de produtos digitais por meio de ferramentas poderosas de disseminação do conhecimento e informação. João Pedro Resende é o fundador da Hotmart. A BEER OR COFFEE, fundada pelos irmãos Pedro e Roberta Vasconcelos, é um aplicativo que reúne os espaços de cowork.

Muito mais do que interação presencial, o compartilhamento é parte fundamental nesses ambientes. As empresas citadas, em especial a Sympla, Hotmart, Sambatech e Beer Or Coffee representam os casos de sucesso da comunidade de startups de Belo Horizonte. Junto a seus fundadores, representam a primeira geração do San Pedro Valley, assim como citado pela Entrevistada 16. As empresas, da primeira geração, que obtiveram projeção dentro do ecossistema, atualmente, representam o SPV como embaixadores da comunidade. 
Do total de entrevistados, 11 deles citaram o Governo de Minas, por meio da SEDECTES, cuja atuação tem sido responsável pelos principais programas de incentivo à inovação e empreendedorismo, como: O SEED, cuja sigla significa Startups and Entrepreneurship Ecosystem Development ou, em português, Startups e Desenvolvimento de Ecossistemas Empreendedores, uma aceleradora de startups, que foi criada pelo Governo de Minas Gerais em busca de empreendedores do mundo inteiro, que acarretam novas aprendizagens e compartilham experiências, sonhos, ideias e principalmente a determinação de construir algo inovador com uma boa ideia de negócio. O SEED MG é baseado em Capital Semente e não exige nenhum tipo de recebimento das ações das startups aceleradas no programa. De acordo com o Entrevistado 2, "O SEED é um grande player, bem forte e, posso destacar que, por ter o governo por trás, é uma mensagem boa para a sociedade, bem importante do que está sendo feito".

As entidades de suporte, apoio e fomento foram citadas por 8 entrevistados, dentre elas, o SEBRAE foi a entidade mais citada seguido pela FUNDEP, FUNDEPAR, SISTEMA S. O SEBRAE é um grande apoiador dos negócios nascentes, sua missão é disseminar a cultura empreendedora e fomentar a competitividade dos pequenos negócios por meio da articulação para criação de políticas públicas; sendo considerado, pelo Entrevistado 1: um importante ator do movimento "e claro, o glorioso SEBRAE é o grande protagonista da catalisação". A FUNDEP realiza o gerenciamento administrativo e financeiro de projetos da UFMG e outros importantes centros de ensino e pesquisa do Brasil. Com atendimento especializado, a Fundação oferece serviços exclusivos como: elaboração das propostas, captação de recursos, compras, importações, contratação de pessoal, assessoria jurídica, prestação de contas, gestão de concursos, entre outros. A Fundepar é uma gestora de Fundos de Investimento especializada no desenvolvimento de negócios inovadores de alto impacto. Apoiamos empresas emergentes por meio do aporte de capital empreendedor e do suporte à gestão, com ênfase na transformação de tecnologias em produtos e serviços de alto valor agregado.

Finalizando os atores fundamentais para o desenvolvimento de um ecossistema robusto, 9 entrevistados citaram os clientes, mercado e a sociedade.

Sobre as formas de interação entre os atores, para 11 dos 18 entrevistados, a interação se dá principalmente por meio das mídias sociais e de eventos, principalmente, que são promovidos por iniciativas individuais dos próprios empreendedores, como happy hours, jantares, festas, etc. De acordo com o Entrevistado 1 "a interação é feita de forma orgânica, não organizada, pois não somos um ecossistema maduro"; o Entrevistado 2 traz que a interação é feita "através de workshops, visitas informais, grupos de Whatsapp do SPV, Telegram, além de emails, redes sociais onde divulgamos o que está acontecendo".

Entre os eventos que promovem a interação, os mais citados estão a FINITI, os Hackatons, o Sebrae Exchange, o Demo DAY: A FINITI é a feira mais inovadora da América Latina sendo um grande HUB de negócios reunindo diversos eventos em um só local, com foco em promover o intercâmbio e fomentar o que há de mais avançado em tecnologia, inovação e empreendedorismo. Os Hackathons são eventos que reúnem programadores, designers e outros profissionais ligados ao desenvolvimento de software para uma maratona de programação, cujo objetivo é desenvolver um software ou solução tecnológica que atenda a um fim específico. $\mathrm{O}$ DEMO DAY, ou dia de demonstração, é um evento onde empreendedores (startups) têm a oportunidade de apresentar seu negócio para investidores de diferentes modalidades de 
investimento, como investidor-anjo, venture capital, private equity, com o objetivo de conseguirem investimento para os seus negócios crescerem.

Quanto ao acesso à informação, as respostas foram bastante alinhadas, uma vez que é uma comunidade digital onde as redes sociais são fortes aliadas, a crença geral é que a informação está disponível e depende do interesse das entidades em buscá-las, filtrá-las e utilizá-las, assim como traz o Entrevistado 6 "As informações estão disponíveis, mas tem que buscar, saber onde buscar e estabelecer bons canais de informação".

Alguns entrevistados atribuem a colaboração entre os participantes à empatia, segundo eles os empreendedores e não apenas os de startup colaboram entre si por já terem passado por todos os problemas que as empresas iniciantes passam. É possível perceber, com as respostas dos entrevistados, que os pilares da colaboração, do senso de retribuição, do give back, give before to get, give first e do propósito são estruturantes nessa comunidade, principalmente estre as startups que participam de programas de pré aceleração e aceleração, uma vez que o senso de retribuição é disseminado nesses programas, o empreendedor que recebeu ajuda para se estabelecer entende que também deve colaborar com outros empreendedores na fase inicial e, assim, cria-se um ciclo virtuoso.

O último bloco de perguntas das entrevistas buscou investigar se há estratégias de desenvolvimento desse ecossistema. De acordo com alguns entrevistados há algumas iniciativas com o intuito de unir forças e otimizar esforços. O que se percebe é que, apesar do ecossistema ser um organismo que se pressupõe, sem liderança, é necessária a existência de entidades ou mecanismos de controle que se assemelhem a uma governança ou conselho ou comitê para que possa concentrar e otimizar esforços para transformá-los em retorno para os empreendedores. O que parece é que sem essa iniciativa a comunidade poderá se tornar apenas uma marca forte com representatividade fraca.

\section{$4 \quad$ Discussão dos resultados e Considerações Finais}

O propósito do trabalho foi analisar os elementos relevantes e como eles interagem para a estruturação de um ecossistema que fomenta o empreendedorismo em uma região, bem como as estratégias que contribuem para o fortalecimento deste ecossistema na qual a comunidade de startups está localizada. Antes da análise das conclusões é importante esclarecer um dos pontos identificados com essa pesquisa, o San Pedro Valley não é o ecossistema de Belo Horizonte, ele é uma comunidade de startups de tecnologia que compõe o ecossistema, no entanto, ao consideramos a amplitude que o termo ecossistema possui, pode-se considerar que SPV é um ecossistema de startups dentro do ecossistema de Belo Horizonte, que por sua vez compõe e interage com o ecossistema mineiro, brasileiro e assim segue essa interação exponencialmente.

Interação entre os atores: Em relação aos elementos relevantes para a caracterização de ecossistema os empreendedores são os grandes protagonistas desse movimento seguidos pelos programas de aceleração que tem sido considerados uma evolução das incubadoras, os investidores, agentes que contribuem além dos recursos financeiros com aconselhamento e mentoria, as universidades, formadoras da mão de obra e provedora de pesquisa, os clientes, considerados grandes incentivadores com seus feedbacks construtivos, as agências de fomento, os espaços de coworks, agentes fundamentais para a conexão dos atores.

Todos os domínios do modelo de ecossistema de Isenberg foram contempladas e estão presentes nos relatos das empresas entrevistadas. A forma de interação desses atores, por não 
haver uma governança, coordenação estruturada ou liderança estabelecida é realizada de forma orgânica por meio de eventos, principalmente, além das mídias sociais como canais do Youtube, perfis do Facebook, Telegram e grupos de Whatsapp.

Colaboração entre os atores: A colaboração entre os atores é uma forte característica da comunidade San Pedro Valley, que enfatiza os valores do give back, give before to get, give first, pilares intensamente trabalhados nos programas de aceleração. No entanto, apesar da colaboração ser natural nesse ambiente, a parceria não é, o que pode ser justificado pela natureza dinâmica do mercado das startups e dos serviços consumidos pelas mesmas que, por serem empresas basicamente de conhecimento, não possuem fornecedores de matérias primas, compras significativas de insumos, etc.

Impacto no desenvolvimento da região: Quando se analisa o impacto no desenvolvimento da região gerado pelo San Pedro Valley, a percepção dos entrevistados fica na esfera comportamental. A sociedade está se transformando à medida que assiste à ascensão dos empreendedores, assim, o San Pedro Valley é um movimento que inspira e que irá marcar a trajetória e a forma de se empreender da próxima geração. De acordo com Filion (1999), se tudo for igual, quanto mais empreendedores uma sociedade tiver e quanto maior for o valor dado, nessa sociedade, aos modelos empresariais existentes, maior será o número de jovens que optarão por imitar esses modelos, escolhendo o empreendedorismo como uma opção de carreira.

Estratégias para o fortalecimento do ecossistema: Em relação às estratégias para promover a perenidade e o fortalecimento do ecossistema, percebe-se que há ações dispersas e isoladas por pequenos grupos, o que demonstra a fragilidade dessas iniciativas e a importância da existência de algo que possibilite convergir tais esforços e revertê-los em sustentabilidade para o ecossistema e prosperidade para as instituições e a sociedade, entretanto, não há um consenso de quem lideraria essa ação.

Cabe ressaltar aqui que há um paradoxo nessa questão pois, ao mesmo tempo que os relatos enfatizam que o SPV não está sob nenhuma direção "não há um chefe, o San Pedro Valley é anárquico nesse sentido" aponta-se a falta de uma organização estruturada para que haja organização das ações, "não tem representatividade, então não é uma organização, não se presta a nenhum papel, então é uma ideia super legal mas nada muito pragmático". Desta forma, a pesquisa demonstra uma demanda latente por alguma estrutura que promova a sinergia das iniciativas, no entanto, não existe consenso e nem propostas.

\section{Referências}

ANDERSON, Alistair R. Conceptualising entrepreneurship as economic'explanation'and the consequent loss of'understanding'. International Journal of Business and Globalisation, v. 14, n. 2, p. 145-157, 2015.

ARRUDA, Carlos; BURCHARTH, Ana; ASSIS, Michelle. Estudos Teóricos Referenciais Sobre Educação Empreendedora. Sebrae, Fundação Dom Cabral. 2015.

AUERSWALD, Philip E. Enabling entrepreneurial ecosystems: Insights from ecology to inform effective entrepreneurship policy. 2015.

CAMPOS, J. G. C.; SCHMITZ; A.; TEIXEIRA; C. S. Coworking Spaces: conceitos, tipologias e características. In: CONGRESSO INTERNACIONAL DE CONHECIMENTO E INOVAÇÃO, 5., 2015, Joinville. Anais... Joinville: Unisociesc, 2015. 
DORNELAS, José Carlos Assis. Empreendedorismo corporativo: conceitos e aplicações. Revista de Negócios, v. 9, n. 2, 2007.

DORNELAS, J. C. A. Empreendedorismo. 2008. Elsevier, Brasil.

ETZKOWITZ, H.; ZHOU, C. Hélice Tríplice: inovação e empreendedorismo universidadeindústria-governo. Estudos Avançados, v.31 (90), 2017.

FILION, Louis Jacques. Diferenças entre sistemas gerenciais de empreendedores e operadores de pequenos negócios. Revista de Administração de Empresas, v. 39, n. 4, p. 6-20, 1999.

GLOBAL ENTREPRENEURSHIP MONITOR (GEM). Empreendedorismo no Brasil 2016. Coordenação de Simara Maria de Souza Silveira Greco. Curitiba: IBQP, 2017.

ISENBERG, Daniel. The entrepreneurship ecosystem strategy as a new paradigm for economic policy: Principles for cultivating entrepreneurship. Presentation at the Institute of International and European Affairs, 2011.

ISENBERG, Daniel J. THE BIG IDEA How to Start an Entrepreneurial Revolution. Harvard Business Review, v. 88, n. 6, p. 40-+, 2010.

MASON, Colin; BROWN, Ross. Entrepreneurial ecosystems and growth oriented entrepreneurship. Final Report to OECD, Paris, v. 30, n. 1, p. 77-102, 2014.

MOORE, James F. Predators and prey: a new ecology of competition. Harvard business review, v. 71, n. 3, p. 75-86, 1993.

MONTENEGRO, Matt. Porque eu parei de acreditar no Give first e Give back e os principais motivos para você fazer o mesmo. 2016. Disponível em: $<$ http://vidadestartup.org/cultura-startup/>. Acesso em: 28 set. 2018.

MOTOMURA, Oscar. Empreendedorismo sustentável. São Paulo, 2004. Disponível em: $<$ http://www.amana-key.com.br>. Acesso em: 11 fev. 2005

OLAVE, Maria Elena León; AMATO NETO, João. Redes de cooperação produtiva: uma estratégia de competitividade e sobrevivência para pequenas e médias empresas. Gest. Prod. [online]. 2001, vol.8, n.3, pp.289-318.

PACELLI, Shirley. BH é Tech: Grupo de startups autogerenciadas querem fortalecer imagem do mercado belo-horizontino, com criação de site. 2012. Disponível em: $<$ https://www.em.com.br/app/noticia/tecnologia/2012/10/25/interna_tecnologia,325549/bh-etech.shtml.> Acesso em: 28 set. 2018.

PEREIRA, Helena Carneiro Baeta. O ecossistema empreendedor de Belo Horizonte: análise do caso San Pedro Valley. 2017.

SAN PEDRO VALLEY. Censo San Pedro Valley. 2015. Disponível em: http://pt.slideshare.net/Sympla/censo-spv-2015. Acesso em: 23 fev. 2018.

SARASVATHY, Saras D. Effectuation: elements of entrepreneurial expertise. 2003.

SHANE, S., VENKATARAMAN, S., The promise of entrepreneurship as a field of research.

The Academy of Management Review, 2000.

SEBRAE. Fatores condicionantes e taxa de mortalidade de empresas no Brasil. Relatório de pesquisa. Brasília, 2004.

TIMMONS, J.A., S MOLLEN, L.E., DINGEE, L.M. New Venture Creation: Entrepreneurship in the 1990s. Homewood, Illinois: Irwin. 2011.

VENKATARAMAN, S. The Distinctive Domain of Entrepreneurship Research. Advances in Entrepreneurship, Firm Emergence And Growth, Vol. 3, pp.119-138, J. Katz, ed., JAI Press, 1997. 